\title{
Design of Doubly Salient Permanent Magnet Motors With Minimum Torque Ripple
}

\author{
Yu Gong ${ }^{1,2}$, K. T. Chau ${ }^{1}$, J. Z. Jiang ${ }^{2}$, Chuang $\mathrm{Yu}^{1}$, and Wenlong $\mathrm{Li}^{1}$ \\ ${ }^{1}$ Department of Electrical and Electronic Engineering, The University of Hong Kong, Hong Kong, China \\ ${ }^{2}$ Department of Automation, Shanghai University, Shanghai 200444 China
}

\begin{abstract}
This paper presents a design approach for doubly salient permanent magnet (DSPM) motors, aiming to minimize the torque ripple. The key is to propose the design criteria that the reluctance of all magnetic paths is the same, and the armature windings can be artfully connected to compensate the variation of self-inductance. Based on these criteria, the magnetic characteristics become symmetric, and the variation of self inductance is suppressed. Thus, the resulting torque ripple can be minimized. By using the time-stepping finite element method, the proposed DSPM motor and the existing DSPM motor are quantitatively compared in terms of their back-EMFs, self-inductances, and torque ripples, hence confirming the validity of the proposed design approach.
\end{abstract}

Index Terms-Doubly salient, permanent magnet motor, self-inductance, torque ripple.

\section{INTRODUCTION}

D OUBLY salient permanent magnet (DSPM) motors are a kind of stator-PM brushless machine, which have the advantages of high efficiency, high power density, robust structure, and freedom from thermal problems on PMs [1]-[3]. Therefore, they are particularly attractive for modern electric vehicles [4]. However, most of the available DSPM motors are designed by an ad hoc approach. Since the relationship between the number of stator poles $N_{s}$, the number of rotor poles $N_{r}$, the number of PM poles $N_{p}$, and the number of phases $m$ has not been carefully studied, they generally suffer from asymmetric flux linkages between the positive and negative cycles as well as between phases, leading to asymmetric back-electromotive force (back-EMF) and, hence, high torque ripple. Also, the corresponding self-inductance has a large variation, resulting in a large reluctance torque and, hence, high torque ripple. Recently, such torque ripple has been alleviated by using control means [5], which inevitably involve additional hardware cost and control complexity.

The purpose of this paper is to propose a new design approach for DSPM motors, thus minimizing the corresponding torque ripple. First, a new design principle will be discussed. Then, the proposed DSPM motor will be analyzed by using the timestepping finite element method (TS-FEM). Hence, a quantitative comparison of torque ripples between the proposed and existing DSPM motors will be given to verify the design approach.

\section{DESIGN PRINCIPLE}

For existing DSPM motors, the back-EMF waveform is generally asymmetric between the left and right cycles as well as between phases. This is due to different levels of magnetic saturation between instances to and from the aligned position as well as different reluctances of magnetic paths. In order to solve this

Manuscript received March 02, 2009. Current version published September 18, 2009. Corresponding author: Y. Gong (e-mail: yugong@eee.hku.hk).

Digital Object Identifier 10.1109/TMAG.2009.2022761 problem, two criteria are formulated. First, the number of phase coils under a PM pole should be different from the number of phases so as to avoid a particular phase winding locating at the same position under each PM pole. This criterion can be represented by

$$
(m+k) N_{p}=m i=N_{s}
$$

where $i$ and $k$ are positive integers and $k<m$. Second, the stator slot pitch should be equal to the angular difference of two adjacent phases that can be expressed in terms of the number of rotor poles and the number of stator poles. This criterion can be expressed as

$$
360 j \pm \alpha=360 N_{r} / N_{s}
$$

where $j$ is a positive integer and $\alpha$ is the stator slot pitch. For instance, when $m=3$ and $N_{p}=6$ are given, it can deduce $N_{s}=24, N_{r}=20$ or 28 , and $\alpha=60^{\circ}$. For the proposed outer rotor arrangement, $N_{r}>N_{s}$, and hence, $N_{r}=28$ should be adopted. It should be noted that the existing DSPM motor in [2]—namely $m=3, N_{p}=6, N_{s}=36$, and $N_{r}=24$ - cannot satisfy the criteria of (1) and (2).

For existing DSPM motors, the variation of self-inductance is large, which is due to the fact that the coils of each phase have the same pattern of variation of self-inductance. The resulting variation of self-inductance per phase is virtually an integer multiple of the variation of self-inductance of each coil. In order to solve this problem, each phase winding is purposely arranged in such a way that the variations of self-inductance of two individual coils are reversed, hence compensating one another.

Based on the above principle, the proposed DSPM motor is designed as shown in Fig. 1, in which Fig. 1(a) depicts the structure with $m=3, N_{p}=6, N_{s}=24$, and $N_{r}=28$ so that the reluctance of all magnetic circuits is the same, while Fig. 1(b) depicts the winding connection in which the self-inductances of coils $A_{1}$ and $A_{2}$ as well as those of $A_{3}$ and $A_{4}$ are reversed. This structure adopts an outer rotor arrangement, with both armature windings and PMs located in the stator. Such an arrangement enables the direct-drive capability and effective utilization of 


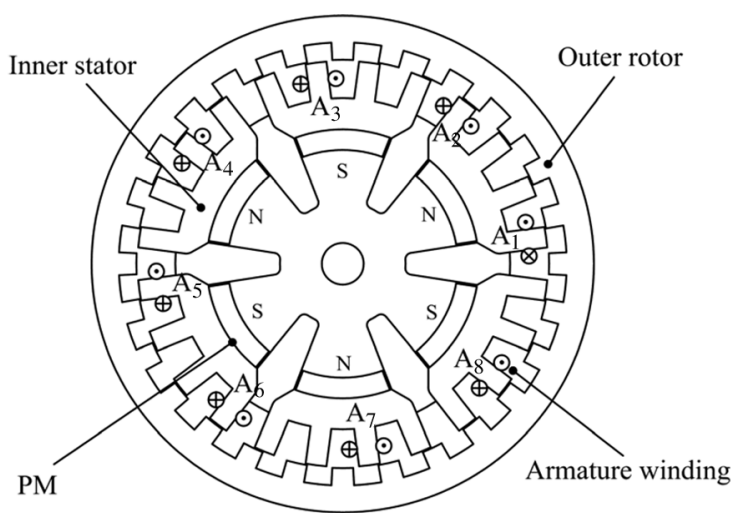

(a)

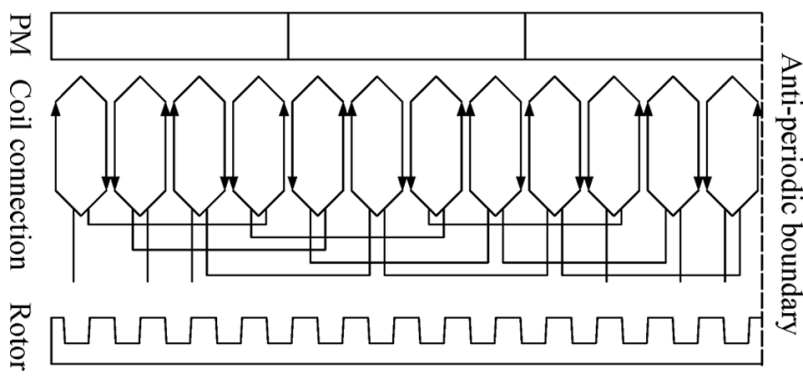

(b)

Fig. 1. Proposed DSPM motor. (a) Structure. (b) Winding connection.

TABLE I

KEY DATA OF PROPOSED DSPM MOTOR

\begin{tabular}{|c|c|}
\hline Rated voltage & $300 \mathrm{~V}$ \\
\hline Rated torque & $10 \mathrm{Nm}$ \\
\hline Speed range & $0-3000 \mathrm{rpm}$ \\
\hline No. of turns per armature coil & 40 \\
\hline No. of stator poles & 24 \\
\hline No. of rotor poles & 28 \\
\hline No. of PM poles & 6 \\
\hline Stator outside diameter & $196.0 \mathrm{~mm}$ \\
\hline Rotor inside diameter & $197.2 \mathrm{~mm}$ \\
\hline Rotor outside diameter & $240.0 \mathrm{~mm}$ \\
\hline Stack length & $80.0 \mathrm{~mm}$ \\
\hline PM remanence & $1.3 \mathrm{~T}$ \\
\hline PM coercivity & $56 \mathrm{kA} / \mathrm{m}$ \\
\hline
\end{tabular}

stator space, which are attractive for electric vehicles. Table I lists the key data of the proposed motor.

\section{ANALYSIS}

In order to assess the validity of the proposed design approach, the characteristics of the proposed DSPM motor are analyzed by using the TS-FEM [6]. Fig. 2 depicts the no-load magnetic field distribution in which magnetic flux lines are very symmetric, indicating that the reluctance of all magnetic circuits is essentially the same. The corresponding air-gap flux density distribution is shown in Fig. 3, in which the flux density can reach $0.9 \mathrm{~T}$. Then, the flux linkage waveforms of four coils $\left(\mathrm{A}_{1}\right.$ to $\left.\mathrm{A}_{4}\right)$ of phase $\mathrm{A}$ in dashed lines, and hence all three phases in solid lines, are shown in Fig. 4. It can be found that

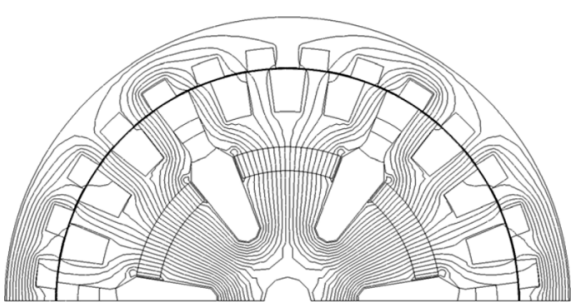

Fig. 2. No-load magnetic field distribution of proposed motor.

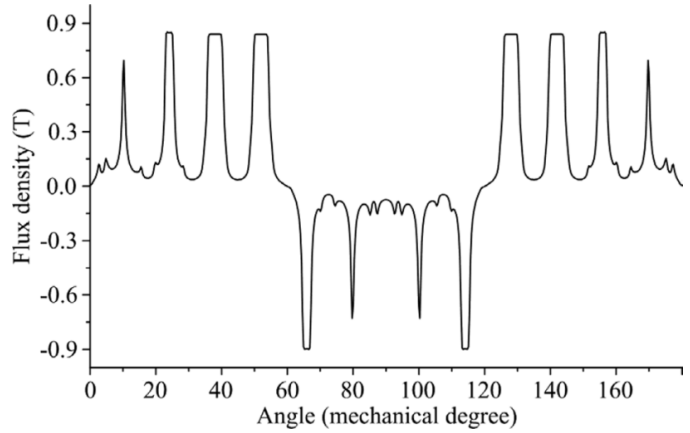

Fig. 3. No-load air-gap flux density distribution of proposed motor.

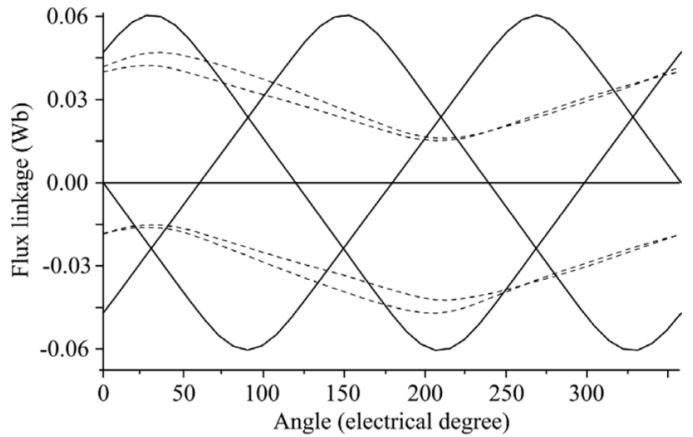

Fig. 4. Flux linkage waveforms of proposed machine (dashed: coils $\mathrm{A}_{1}-\mathrm{A}_{4}$ of phase A, solid: three phases).

the flux linkages of coils $\mathrm{A}_{1}$ to $\mathrm{A}_{4}$ have nearly zero phase shifts. Hence, the variation of flux linkage per phase can be maximized, thus achieving a high back-EMF constant. Also, since these flux linkage waveforms are symmetric with almost linear rise-up and fall-off slopes, the resulting back-EMF waveforms (solid lines) are symmetric and exhibit a wide flat-top range as shown in Fig. 5. This feature enables the proposed motor, offering a very trapezoidal waveform that is highly desirable for brushless $\mathrm{dc}$ operation with high power density. In contrast, the back-EMF waveforms (dashed lines) of the existing DSPM motor [2] are also plotted in Fig. 5 for direct comparison. It is obvious that the proposed DSPM motor can provide much more symmetric, wider flat-top, and more trapezoidal back-EMF waveforms than the existing one.

Due to the doubly salient structure, the phase winding usually possesses low inductances at the aligned position due to magnetic saturation and also at the unaligned position due to low permeance, whereas the maximum inductance occurs when the poles are about half overlapping. As a result, the reluctance torque and thus torque ripple are produced. In order to assess 


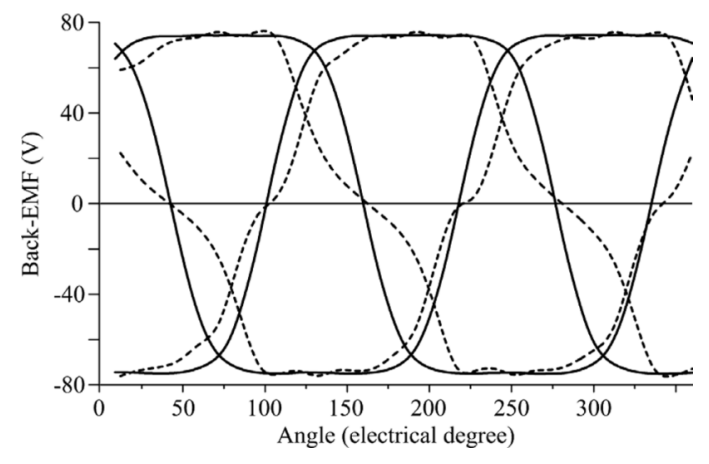

Fig. 5. Comparison of back-EMF waveforms (dashed: existing, solid: proposed).

the inductance of the proposed DSPM motor, a method [7] that takes magnetic saturation into account is adopted

$$
\begin{aligned}
L_{\mathrm{a}} & =\frac{\psi_{\mathrm{aa}}-\psi_{\mathrm{pm}}}{I_{\mathrm{a}}} \\
M_{\mathrm{ab}} & =\frac{\psi_{\mathrm{ab}}-\psi_{\mathrm{pm}}}{I_{\mathrm{b}}}
\end{aligned}
$$

where $L_{\mathrm{a}}$ is the self-inductance of phase A, $M_{\mathrm{ab}}$ is the mutual inductance between phases A and $\mathrm{B}, \Psi_{\mathrm{aa}}$ is the flux linkage of phase A due to the PM and phase A current $I_{\mathrm{a}}, \Psi_{\mathrm{ab}}$ is the flux linkage of phase A due to the PM and phase B current $I_{\mathrm{b}}$, and $\Psi_{\mathrm{pm}}$ is the flux linkage of phase A due to the PM only. Hence, the self-inductance waveforms of coils $\mathrm{A}_{1}$ and $\mathrm{A}_{2}$ at the rated positive and negative currents are simulated as shown in Fig. 6. It can be observed that the variations of self-inductance of the two coils are similar to those of the conventional DSPM motor. However, their variations are reversed. Similar variations can be found for the coils $\mathrm{A}_{3}$ and $\mathrm{A}_{4}$. Therefore, when connecting them in series, the resulting variation of self-inductance can be significantly diminished.

Consequently, the self-inductance waveform of four coils $\left(\mathrm{A}_{1}\right.$ to $\mathrm{A}_{4}$ ) of phase $\mathrm{A}$ and the corresponding mutual inductance waveform between phases A and B are simulated as shown in Fig. 7. It can be seen that the mutual inductance is much smaller than the self-inductance and, hence, negligible, which is actually due to the nature of concentrated windings. Moreover, the overall self-inductance waveform of coils $A_{1}$ to $A_{8}$ of phase $A$ of the proposed DSPM motor is plotted together with that of the existing motor [2] as shown in Fig. 8. It confirms that the proposed motor can offer much smaller variation of self-inductance, hence much lower torque ripple.

\section{TORQUE RIPPLE}

The electromagnetic torque $T_{\mathrm{em}}$ of the DSPM motor can be expressed as

$$
T_{\mathrm{em}}=\frac{1}{2} i^{2} \frac{d L}{d \theta_{r}}+i \frac{d \psi_{\mathrm{pm}}}{d \theta_{r}}=T_{\mathrm{r}}+T_{\mathrm{pm}}
$$

where $L$ is the phase inductance, $i$ is the phase current, $\theta_{r}$ is the mechanical rotor position, $T_{\mathrm{pm}}$ is the PM torque component

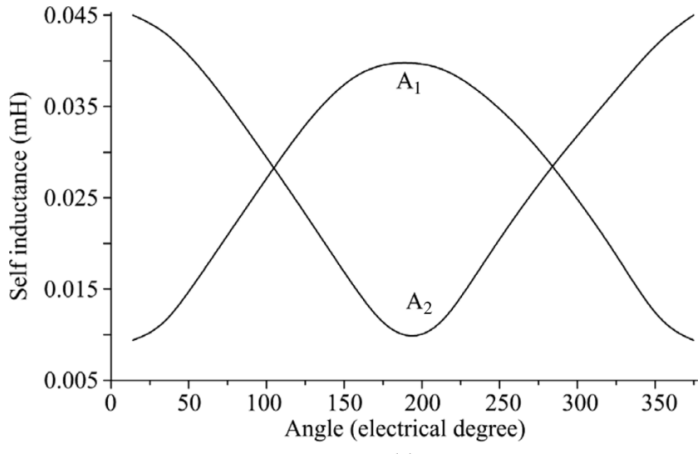

(a)

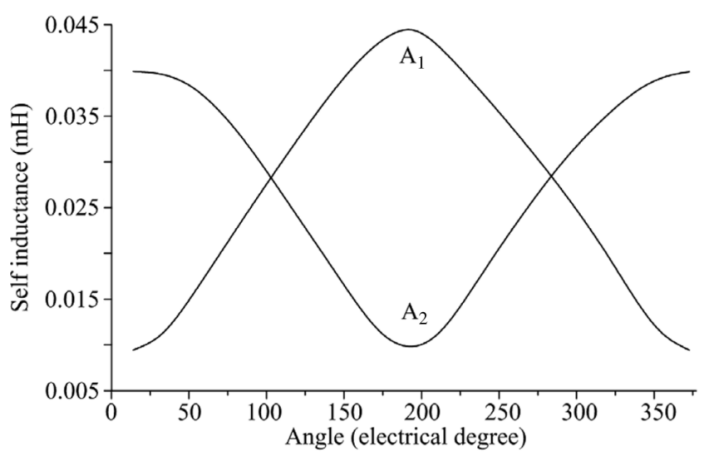

(b)

Fig. 6. Self-inductance waveforms of coils $A_{1}$ and $A_{2}$. (a) Positive current. (b) Negative current.

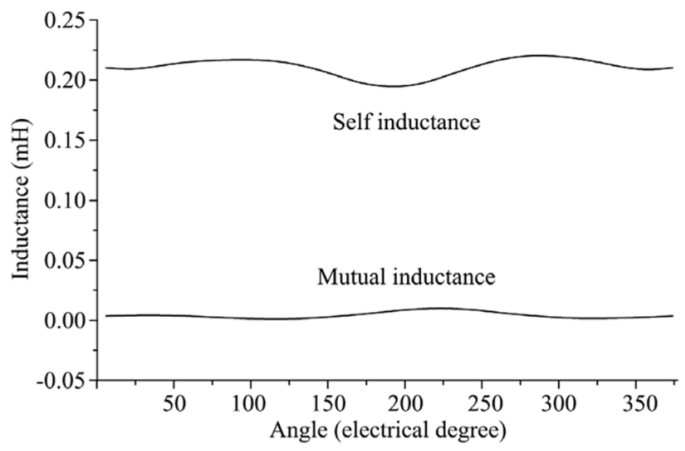

(a)

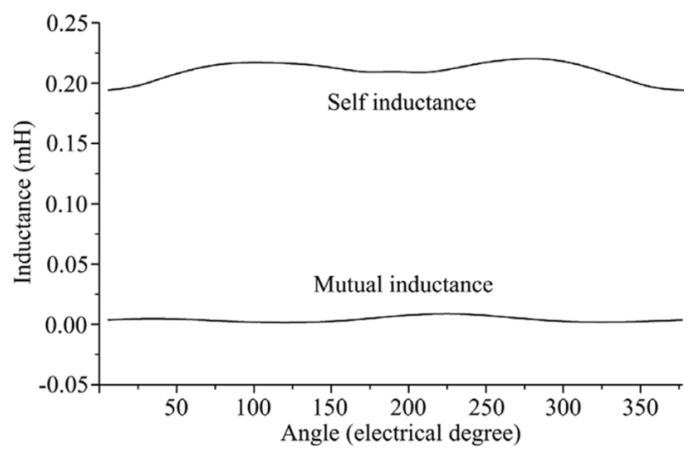

(b)

Fig. 7. Self- and mutual inductance waveforms of coils $A_{1}$ to $A_{4}$ of phase $A$. (a) Positive current. (b) Negative current.

due to the interaction between armature current and PM flux linkage, and $T_{\mathrm{r}}$ is the reluctance torque component due to the variation of self-inductance. It should be noted that $T_{\mathrm{pm}}$ is the 


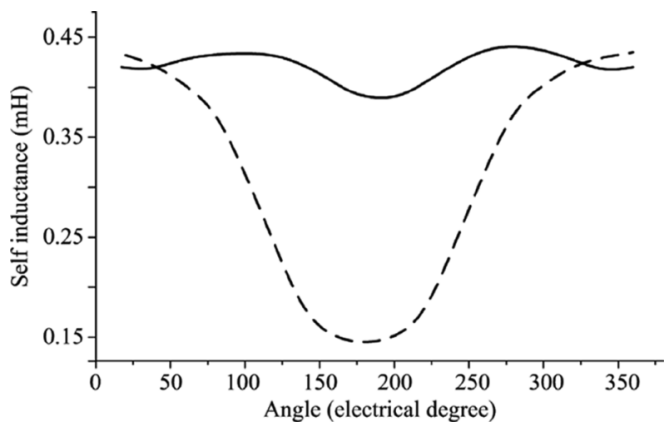

Fig. 8. Comparison of self-inductance waveforms of coils $A_{1}$ to $A_{8}$ of phase $A$ (dashed: existing, solid: proposed).

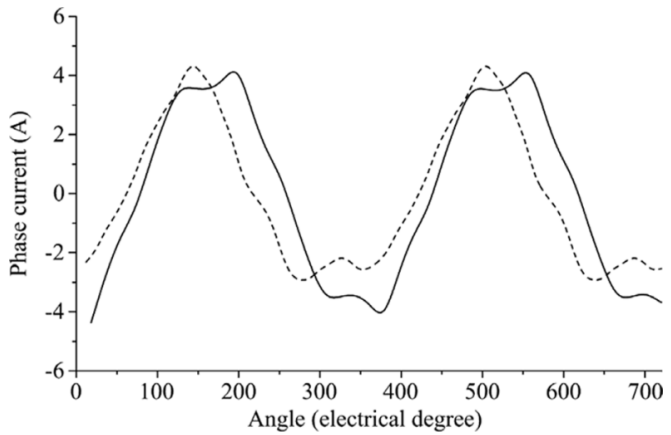

Fig. 9. Comparison of phase-current waveforms (dashed: existing, solid: proposed).

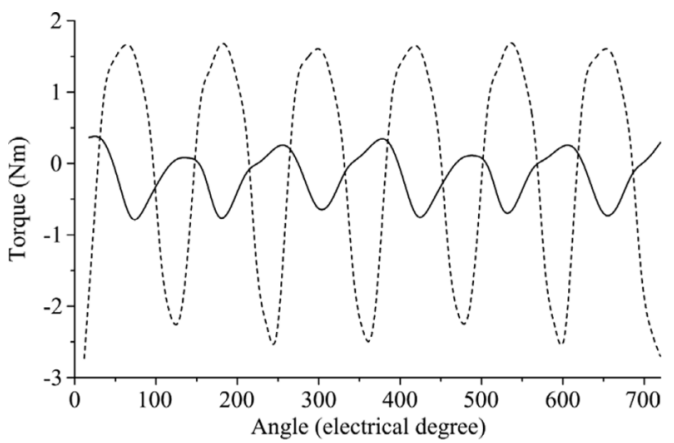

Fig. 10. Comparison of reluctance torque waveforms (dashed: existing, solid: proposed).

driving torque, whereas $T_{\mathrm{r}}$ is pulsating and noncontributive to the driving torque.

Fig. 9 shows the phase-current waveforms of both the proposed and existing DSPM motors under the same operating condition. It can be observed that the waveform of the existing one is asymmetric between the positive and negative cycles, which is actually due to different reluctances and different saturation levels of magnetic circuits. In contrast, the waveform of the proposed one is symmetric, leading to production of less torque ripple. Fig. 10 shows a comparison of their $T_{\mathrm{r}}$ waveforms, confirming that the magnitude can be significantly reduced by about $65 \%$. Thus, the corresponding torque ripple can be significantly suppressed. Taking into account $T_{\mathrm{pm}}$, their $T_{\mathrm{em}}$ waveforms are also compared, as depicted in Fig. 11, which confirms that the proposed DSPM motor has much lower torque ripple than the existing one. Quantitatively, the torque ripple factor of the pro-

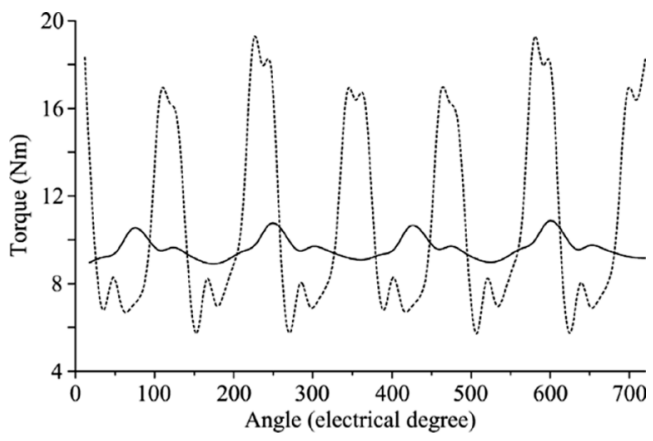

Fig. 11. Comparison of electromagnetic torque waveforms (dashed: existing, solid: proposed).

posed motor, which is defined as the ratio of peak-to-peak value to average value, is about $20 \%$, while that of the existing one is about $110 \%$.

It should be noted that such improvement in torque ripple is based on the use of simple voltage control with $120^{\circ}$ conduction period. If specific current control is employed, the torque ripple of the existing motor will be better so that the improvement due to the proposed design will be reduced.

\section{CONCLUSION}

In this paper, a new design approach has been proposed for the DSPM motor, which can significantly minimize the torque ripple as compared to the existing one. Based on the proposed design criteria, the resulting back-EMF closely resembles a symmetric trapezoidal waveform, and the variation of self-inductance is greatly suppressed. By using the TS-FEM, the proposed DSPM motor and the existing DSPM motor are quantitatively compared, hence confirming the validity of the proposed design approach.

\section{ACKNOWLEDGMENT}

This work was supported by the Research Grants Council, Hong Kong Special Administrative Region, China, under Grant HKU 7105/07E.

\section{REFERENCES}

[1] Y. Liao, F. Liang, and A. Lipo, "A novel permanent magnet motor with doubly salient structure," IEEE Trans. Ind. Appl., vol. 31, no. 5, pp. 1069-1078, Sep.-Oct. 1995.

[2] C. Liu, K. T. Chau, J. Z. Jiang, and S. Niu, "Comparison of statorpermanent-magnet brushless machines," IEEE Trans. Magn., vol. 44, no. 11 , pp. $4405-4408$, Nov. 2008.

[3] C. Yu, K. T. Chau, X. Liu, and J. Z. Jiang, "A flux-mnemonic permanent magnet brushless motor for electric vehicles," J. Appl. Phys., vol. 103, no. 7, pp. 07F103:1-07F103:3, Apr. 2008.

[4] K. T. Chau, C. C. Chan, and C. Liu, "Overview of permanent-magnet brushless drives for electric and hybrid electric vehicles," IEEE Trans. Ind. Electron., vol. 55, no. 6, pp. 2246-2257, Jun. 2008.

[5] K. T. Chau, Q. Sun, Y. Fan, and M. Cheng, "Torque ripple minimization of doubly salient permanent magnet motors," IEEE Trans. Energy Convers., vol. 20, no. 2, pp. 352-358, Jun. 2005.

[6] Y. Wang, K. T. Chau, C. C. Chan, and J. Z. Jiang, "Transient analysis of a new outer-rotor permanent-magnet brushless dc drive using circuitfield-torque time-stepping finite element method," IEEE Trans. Magn. vol. 38, no. 2, pp. 1297-1300, Mar. 2002.

[7] Z. Q. Zhu, Y. Pang, D. Howe, S. Iwasaki, R. Deodhar, and A. Pride, "Analysis of of electromagnetic performance of flux-switching permanent-magnet machines by nonlinear adaptive lumped parameter magnetic circuit model," IEEE Trans. Magn., vol. 41, no. 11, pp. 4277-4286, Nov. 2005. 